\title{
OTIMIZAÇÃO DE PROCEDIMENTO DE MANUTENÇÃO PARA RECUPERAÇÃO DE ROLOS DE LINGOTAMENTO CONTÍNUO DO PROCESSO PRODUTIVO DE AÇO
}

\author{
Brenno Carneiro do Nascimento (FACULDADE MULTIVIX - VITÓRIA) \\ brenno.carneiro7@hotmail.com \\ Isabella Hadadd Rebello (FACULDADE MULTIVIX - VITÓRIA) \\ isabellahrebello@gmail.com \\ Mateus Borlini Rizzo (FACULDADE MULTIVIX - VITÓRIA) mborlini1@gmail.com \\ Elias Rocha Gonçalves Júnior (FACULDADE MULTIVIX - VITÓRIA) \\ eliasrgjunior1@gmail.com \\ Virgínia Siqueira Gonçalves (UNIVERSIDADE CANDIDO MENDES) \\ virginiasiqueiragoncalves@gmail.com
}

\section{Resumo}

Este trabalho teve como objetivo analisar a aplicação do procedimento de recuperação de rolos do lingotamento contínuo através da soldagem por arco submerso utilizando processos específicos. Foi realizado ensaio de ultrassom nos rolos para identificar a profundidade das trincas no revestimento duro do rolo, sendo que este possui uma espessura de $8 \mathrm{~mm}$. Foi realizado o procedimento de soldagem de um rolo no tempo total de 42 horas considerando o preparo da solda e a deposição de material soldado, com a espessura de $7 \mathrm{~mm}$ por camada depositada, no total de 6 camadas de solda. Após a soldagem, os rolos passaram por um tratamento térmico para alívio de tensão nos munhões, onde ficaram por horas até o processo final do tratamento. O procedimento adotado garante a otimização do processo de manutenção, destacando as variáveis relevantes a serem observadas e rotinas de processo bem delineadas, o que garante uniformidade e permite melhor controle dos responsáveis pelos setores de gerenciamento de manutenção e de gestão de ativos, assim pode-se concluir que, quando adotado e realizado conforme estabelecido, a recuperação dos rolos é viável.

Palavras-Chave: Otimização de processos, produção de aço, rolos de lingotamento contínuo, gerenciamento de manutenção.

\section{Introdução}

A produção de aço possui vários processos, desde a extração minério de ferro a fabricação de placa e bobinas de aço bruto, que depois será processado e encaminhado para as indústrias automobilísticas e outros fins (COELHO, 2013). A produção de placa e bobinas é feita pelo processo de lingotamento contínuo e pelo laminador de tiras a quente (LTQ), estes possuem 
rolos por onde passam as placas e bobinas já laminadas prontas para serem enroladas. Esses equipamentos com o tempo sofrem desgaste, assim necessitando de recuperação para voltarem a linha de produção.

A laminação a quente consiste num processo de deformação de metal através da passagem entre dois cilindros rotatórios que giram em sentidos opostos, a força de atrito ocasionada pelo contato do material e o rolo ocasiona a deformação (BRESCIANI FILHO, 2011). Estas superfícies, em condições de contato exercem cargas intensas entre si, o que ocasiona a deformação plástica, até que a área de contato se adeque ao carregamento o qual está exposto (ROY, 2013).

Conforme Rodrigues (2017), são utilizados durante o processo de produção das placas e bobinas de aço vários equipamentos, entre eles estão os rolos que podem ser classificados como rolos puxadores (pinch roll), rolos abraçadores (wrapper rolls), rolos alimentadores (feed roll) e rolos de mesa (table roll). O grande desafio para a recuperação destes rolos é sua durabilidade na linha de produção, ou seja, o produto após recuperado precisa apresentar um tempo de vida considerável para tornar-se viável o processo.

De acordo com a utilização dos rolos pela empresa A, após ser encaminhado para reparo, foram diagnosticadas trincas referentes a fadiga sofrida pelos rolos, sendo estas observadas e obtido resultado de que a trinca de maior profundidade obteve $6 \mathrm{~mm}$. Essas trincas impossibilitam o reparo sem que haja alguma interferência sobre elas, assim será realizado um procedimento para que possibilite a recuperação dos rolos sem que haja a aparição de trincas no final do processo, possibilitando o maior rendimento e melhor aproveitamento de recursos para o procedimento.

O objetivo desse estudo é propor o processo de recuperação dos rolos, a fim de recolher informações que identifiquem as possíveis causas para a trincas e encontrando uma solução possível e viável para o processo. Para tal foram propostos procedimentos como usinagem, soldagem do tipo MIG e arco submerso, tratamento térmico para alívio de tensões e teste de dureza Rockwell, sendo todos os procedimentos realizados com grande precisão para garantir a qualidade desejada.

\section{Referencial Teórico}

Desgaste e altas temperaturas geram condições severas que os componentes de engenharia têm que suportar em muitas aplicações (BLAU, 2010). Portanto, as superfícies dos 
componentes devem ser tratadas para resistir a essas condições adversas, proporcionando desempenho desejado e vida útil de serviço (ZHENG et al., 2017). As técnicas mais frequentemente usadas para aplicação de revestimentos metálicos são: cladeamento, imersão a quente, aspersão térmica, eletrodeposição, cementação, deposição em fase gasosa e redução química, além de revestimento por soldagem (GENTIL, 2007).

Durante o processo de recuperação, vários fatores são importantes para que esta possa ser possível e viável. Portanto, deve se utilizar um procedimento específico para cada tipo de rolo, porém alguns métodos como limpeza, inspeção, pré-usinagem e realização de teste não destrutivo como, liquido penetrante ou partícula magnética, ultrassom e composição química da região a ser soldada são imprescindíveis em todos os processos de recuperação, para determinar o procedimento que irá se tornar o mais viável para a recuperação dos rolos de acordo com seu estado inicial.

Devido ao esforço mecânico e a falha de deposição na solda aparição de trincas ou poros é inevitável (NELSON et al., 2000), caso isto ocorra, estes materiais devem ser usinados até a retirada total do revestimento duro ou da descontinuidade, assim garantindo uma boa aplicação de soldagem, após a retirada destas descontinuidades, o teste de ultrassom e líquido penetrante devem ser realizados para garantir a completa retirada destes defeitos. Após a retirada completa dos defeitos a região onde será depositado, o substrato deve ser compatível com o material adicionado (PHILLIPS, 2015).

A aplicação de revestimento duro tem como objetivo diminuir o desgaste dos equipamentos e aumentar sua resistência mecânica, assim diminuindo a vida útil do equipamento, buscando assim reduzir as paradas para a manutenção. Uma seleção correta de material a ser depositado, permite entre outras coisas transformar matérias que usualmente não poderiam ser recuperados em materiais recuperáveis, aumentar a resistência e promover melhorias estruturais para as propriedades desejadas (ULUTAN et al., 2011).

De acordo com Rodrigues (2017), para que uma recuperação seja satisfatória, tanto no ponto de vista financeiro quanto de qualidade do trabalho realizado, durante o processo de recuperação, vários pontos devem ser observados. Um dos principais pontos a ser observado será o procedimento de recuperação, no qual estarão descritos todos os passos para que o procedimento seja executado, como material utilizado, a temperatura de pré-aquecimento e interpasse, utilização de consumíveis e o procedimento de soldagem a ser utilizado. Um ensaio de ultrassom e de líquido penetrante deve ser realizado antes da liberação dos rolos, para que seja constatada a viabilidade do procedimento. Caso o material atinja os níveis 
esperados, o procedimento será válido e o rolo poderá ser enviado novamente para a operação.

\section{Material e Métodos}

De acordo com o catálogo disponibilizado pela DIFERRO (2018), representante de aços especiais, o material de composição dos rolos do Lingotamento Contínuo é o aço SAE 4140. Este material possui em sua composição elementos que permitem um melhor desempenho durante sua operação, conforme informações apresentadas na Tabela 1.

Tabela 1 - Composição química (\%) do aço SAE 4140

\begin{tabular}{lcccccccc}
\hline $\begin{array}{l}\text { Elemen } \\
\text { to }\end{array}$ & $\mathbf{C r}$ & Mo & Mn & $\mathbf{C}$ & $\mathbf{S i}$ & $\mathbf{S}$ & $\mathbf{P}$ & $\mathbf{F e}$ \\
\hline SAE & $0,8-$ & 0,15 & 0,75 & 0,38 & 0,15 & 0,04 & 0,03 & Bal. \\
4140 & 1,1 & - & $-1,0$ & - & - & máx. & 5 & \\
& & 0,25 & & 0,43 & 0,30 & & máx. & \\
& & & & & & & & \\
\hline
\end{tabular}

Fonte: Adaptado de DIFERRO (2018)

Inicialmente, após ser retirado de operação, o rolo é encaminhado para a oficina onde será preparado para posteriormente dar continuidade ao processo de recuperação. O procedimento tem início na usinagem da mesa e dos munhões, para que possa ser retirado as trincas presentes que impossibilitam a recuperação e que ocasionariam uma possível ruptura nos munhões posteriormente.

Será realizado o procedimento de soldagem de um rolo, em um tempo total de 42 horas, considerando o preparo da solda e a deposição de material soldado, com uma espessura de 7 mm por camada depositada, no total de seis camadas de solda tornando possível a anotação de dados para análise. O procedimento de soldagem utilizado para soldar a mesa dos rolos parte onde ocorre o contato com o material laminado é o processo de arco submerso, que possibilita um melhor rendimento em relação ao tempo utilizado para soldagem. Antes de aplicar a solda por arco submerso é soldado um anel denominado "anel de sacrifício" na mesa do rolo, o qual impede a passagem de solda da mesa para os munhões. 
Para a soldagem dos munhões, o procedimento de solda adotado é o processo MIG, que torna um possível um melhor controle das variáveis de processo, além de tornar possível alcançar locais onde com o arco submerso seria de difícil acesso. O procedimento é o mesmo realizado para os dois lados. O procedimento utiliza um arame do tipo tubular para a soldagem, a polaridade da corrente é positiva do tipo alternada e é utilizado uma voltagem de $29 \mathrm{~V}$. O rolo precisa ser aquecido durante o processo de soldagem e manter a temperatura dentro de uma determinada faixa, não podendo ocorrer variações de grande oscilação. O controle de temperatura deve ser avaliado a cada $15 \mathrm{~min}$, assim tornando possível um maior controle não fugindo do procedimento adotado. A velocidade periférica utilizada durante o procedimento é de $305 \mathrm{~mm} / \mathrm{min}$, assim tornando possível uma boa deposição de material durante a soldagem.

Por fim, propõe-se a usinagem dos rolos com o objetivo de retirar o excesso de material duro depositado pelo processo de soldagem do rolo, assim este alcançará suas dimensões finais, ou seja, um melhor acabamento superficial, para posteriormente ser colocado em operação. A usinagem final é o último passo da recuperação, tornando-se necessário uma grande precisão durante a usinagem. Caso ocorra algum erro neste processo, o rolo terá que passar pelo processo de recuperação novamente, aumentando custos e adicionando horas de retrabalho ao mesmo.

Após o término do procedimento de recuperação, foram realizados os ensaios de dureza no rolo nos ângulos de $0^{\circ}, 90^{\circ}, 180^{\circ}$ e $270^{\circ}$ (Figura 1), sendo que a dureza desejada para à adequação dos rolos na produção da empresa deve variar entre 52-56 HRC, pois o endurecimento excessivo do material leva-o a fragilidade (FOSTER, 1971). Cabe destacar que uma dureza inferior a faixa apresentada acarretará em um desgaste prematuro do rolo levando a uma vida útil menor. Foram realizadas duas medições em cada um dos ângulos propostos.

Figura 1 - Rolo de lingotamento contínuo preparado para os ensaios de dureza

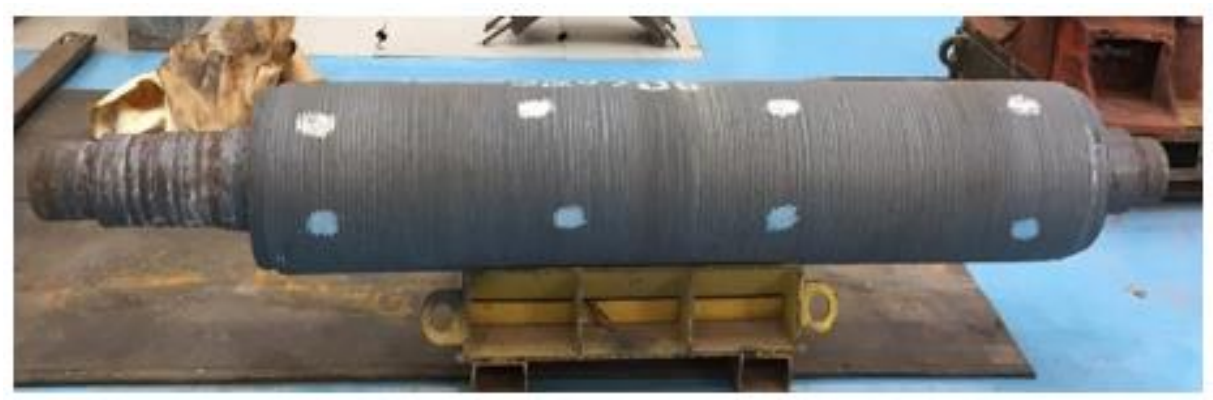

Além destes, propõe-se a realização de um ensaio não-destrutivo de líquido penetrante antes da liberação dos rolos, para que seja constatada a viabilidade do procedimento. Caso o 
material atinja os níveis esperados na avaliação de possíveis descontinuidades remanescentes após a manutenção, o procedimento será válido e o rolo poderá ser enviado novamente para a operação.

\section{Resultados e Discussão}

Foi constatado que a trinca possui profundidade de $6 \mathrm{~mm}$ sendo o material duro do rolo possui uma espessura de $8 \mathrm{~mm}$. Para garantir que seriam retiradas todas as trincas e que o erro não voltasse a acontecer posteriormente, foi estabelecida a retirada de todo o material duro de revestimento, em torno de $8 \mathrm{~mm}$ em seu raio. Após a retirada do material e de todas as possíveis trincas, o rolo é encaminhado para a área de soldagem onde foi preenchido até seu diâmetro final.

De acordo com o acompanhamento do procedimento de soldagem da mesa dos munhões na empresa A, foram observados a polaridade positiva e deslocamento da tocha operacional em todos os processos. Em todo o procedimento das camadas, foram utilizados dois cabeçotes de solda, o arame com bitola de 3,2 $\mathrm{mm}$ e velocidade de 105 polegadas/min, sendo utilizados dois tipos de arame, o arame depositado na almofada foi o KST F6 o qual possui propriedades mecânicas de menor dureza para uma melhor absorção de impacto, para o revestimento duro foi utilizado o arame KST 760 UP, um material de maior resistência ao desgaste e maior dureza para aumentar a vida útil do rolo.

Com relação ao aterramento, o lado fixo e o lado livre são menores que $1 \mathrm{ohm}$ de resistência. O equipamento possui uma voltagem de 29 volts, com taxa de amperagem dos cabeçotes (esquerdo e direito) de 525 ampère. A distância entre o bico de contato e a peça a ser soldada (Stick-out) foi de $32 \mathrm{~mm}$. O equipamento apresenta uma velocidade periférica de 305 $\mathrm{mm} / \mathrm{min}$, foi utilizado fluxo inerte não reagente fabricado pela Kestra de denominação KST, não foram utilizadas larguras e frequências de oscilação. O cordão de solda possui largura de $23 \mathrm{~mm}$, o passo da espiral é de $15 \mathrm{~mm}$, a temperatura de pré-aquecimento de $300^{\circ} \mathrm{C}$ na almofada, e $425^{\circ}$ no restante do processo.

Também foi constatado a não formação de trincas e poros após o processo de usinagem final, assim tornando o procedimento viável. Após todos os procedimentos serem realizados, podese observar que as medidas finais do rolo estão de acordo com as tolerâncias propostas, isto significa que o equipamento pode ser liberado novamente para operação (Tabela 2). 
Tabela 2 - Dimensões finais dos rolos após a realização do procedimento de manutenção.

\begin{tabular}{|c|c|c|c|}
\hline \multirow{2}{*}{$\begin{array}{l}\text { Itens checados } \\
\text { Diâmetro encaixe da bucha Munhão Extr. }\end{array}$} & \multirow{2}{*}{$\begin{array}{l}\text { Medida } \\
(\mathbf{m m}) \\
\varnothing 145\end{array}$} & \multicolumn{2}{|c|}{ Tolerância(+/-) } \\
\hline & & 144,97 & 145,00 \\
\hline Diâmetro da pista do Rolam. Munhão Extr. & $\varnothing 140$ & 139,82 & 139,92 \\
\hline Comprimento total do munhão & 194 & 192,00 & 196,00 \\
\hline \multicolumn{4}{|l|}{ Extremidade } \\
\hline Comprimento da Pista Rolam. Munhão & 117 & 116,70 & 117,30 \\
\hline \multicolumn{4}{|l|}{ Extr. } \\
\hline Face Munhão Extr. Até Encaixe Tampa de & 16 & 15,00 & 17,00 \\
\hline \multicolumn{4}{|l|}{ Boqueio } \\
\hline Diâmetro de encaixe da junta rotativa & 59 & 59,00 & 59,90 \\
\hline \multirow[t]{2}{*}{ Comprimento total do rolo } & 1298 & 1295,0 & 1299,20 \\
\hline & \multicolumn{3}{|c|}{0} \\
\hline Comprimento total da mesa & 985,5 & 980,50 & 986,30 \\
\hline Comprimento alojamento tubo de & 1242 & 1202,0 & 1252,00 \\
\hline Refrigeração & & 0 & \\
\hline Diâmetro encaixe da bucha Munhão & $\varnothing 165$ & 165,04 & 165,08 \\
\hline \multicolumn{4}{|l|}{ Central } \\
\hline Diâmetro da pista do Rolam. Munhão & $\varnothing 140$ & 139,83 & 139,92 \\
\hline \multicolumn{4}{|l|}{ Central } \\
\hline Comprimento total do munhão Central & 132 & 131,90 & 133,00 \\
\hline Face do Munhão até o início da mesa & 102,5 & 102,00 & 103,00 \\
\hline Comprimento da Pista Rolam. Munhão & 86,7 & 86,40 & 87,00 \\
\hline \multicolumn{4}{|l|}{ Central } \\
\hline Profundidade da Tampa de Bloqueio & 10,7 & 10,50 & 10,90 \\
\hline Diâmetro da Mesa & $\varnothing 295$ & 294,87 & 295,00 \\
\hline
\end{tabular}

Fonte: Elaborado pelos autores. 
Como ressalta Baptista (2002), os parâmetros de usinagem interferem diretamente na resistência do material e na sua medida de dureza final, caso o avanço seja fora do estabelecido pelo projeto, a variação de temperatura na peça e na pastilha utilizada pode levar a uma elevação de dureza fora do esperado. Caso não seja possível reduzir a dureza do material no processo de usinagem, através da retirada de material duro presente na peça, o procedimento de recuperação deve ser realizado novamente por completo.

Os dados foram obtidos através de medidas feita com durômetro digital com contato direto na peça, as áreas A, B e C, correspondem respectivamente à parte próxima ao munhão de menor diâmetro, lado B área localizada próxima ao munhão de maior diâmetro e área $\mathrm{C}$, localizada no interior do rolo. A área onde as medidas foram realizadas, necessitou da retirada superficial do material depositado pela soldagem, visto que a solda poderia atrapalhar na medição de dureza. Estes dados foram compilados e estão dispostos na Tabela 3.

Tabela 3 - Valores de dureza Rockwell C obtidos no rolo nos ângulos de $0^{\circ}, 90^{\circ}, 180^{\circ}$ e $270^{\circ}$ nas posições $\mathrm{A}, \mathrm{B}$ e $\mathrm{C}$.

\begin{tabular}{cccc}
\hline Ângulo $\left(^{\mathbf{0}}\right)$ & A & B & C \\
\hline 0 & 52,6 & 55,7 & 54,1 \\
& 55,4 & 53,7 & 53,8 \\
90 & 54,9 & 52,6 & 54,6 \\
& 52,7 & 53,1 & 53,7 \\
180 & 55,8 & 54,5 & 53,8 \\
& 52,6 & 53,9 & 54,6 \\
270 & 54,5 & 54,2 & 53,7 \\
& 55,4 & 55,0 & 55,1 \\
\hline
\end{tabular}

Fonte: Elaborado pelos autores.

As durezas resultaram em uma média de 54,2 HRC, uma média boa visto que se localiza aproximadamente no meio da faixa de dureza desejada. Foi constatado um desvio padrão de 0,98 o que garante que a dureza do rolo está aceitável para que o rolo volte a operação. Os 
valores de dureza de um revestimento possibilitam uma avaliação prévia da variação das propriedades mecânicas, sendo estas dependentes dos parâmetros do processo de soldagem (BLAU, 2010).

Para observar a possível formação de descontinuidades superficiais decorrentes do processo de soldagem, foi utilizado o ensaio de líquido penetrante (Figura 2). Após sua realização e análise, não se constatou a presença de descontinuidades no cordão de solda e, por consequência, o rolo foi aprovado para operação.

Figura 2 - Faixa do rolo na qual foi realizado o ensaio de liquido penetrante.

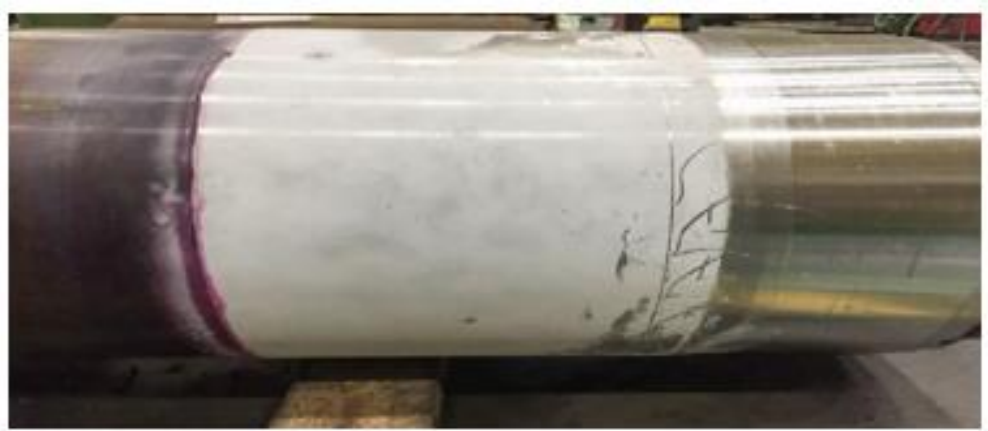

As variações de temperatura na soldagem influenciam na microestrutura do revestimento, nas dimensões finais de uma peça e na microestrutura da mesma, o que pode resultar em efeitos indesejado, como tensões residuais e distorção da estrutura soldada, variação de propriedades mecânicas e descontinuidades (PHILLIPS, 2015). Portanto, o controle adequado dos parâmetros utilizados no processo foi vital para a correta recuperação dos rolos e consequente ausência de descontinuidades superficiais.

\section{Conclusão}

Este trabalho teve como objetivo analisar a aplicação do procedimento de recuperação de rolos do lingotamento contínuo através da soldagem por arco submerso utilizando processos específicos. Diante dos resultados analisados após todo o procedimento pode-se concluir que os métodos adotados atendem as expectativas e as exigências a serem utilizadas, a fim de tornar viável a recuperação dos rolos.

Foi constatado nas análises que o controle de temperatura durante a soldagem foi fundamental para um bom resultado, visto que caso a peça soldada sofra uma variação de 
temperatura fora da faixa desejada, a estrutura do material é comprometida, tornando assim o procedimento inviável.

Durante o tratamento térmico para alívio de tensões, a temperatura de todo processo deve ser rigidamente controlada, pois um aquecimento superior ao esperado ou fora da linha projetada pode ocasionar em falhas catastróficas na estrutura da peça, o resfriamento deve ser controlado de maneira que a peça não sofra uma perda de temperatura brusca ocasionando assim a tempera do material, o que levará no aumento da dureza superficial do rolo levando assim a uma possível ruptura durante a realização do trabalho na área.

O procedimento adotado garante a otimização do processo de manutenção, destacando as variáveis relevantes a serem observadas e rotinas de processo bem delineadas, o que garante uniformidade e permite melhor controle dos responsáveis pelos setores de gerenciamento de manutenção e de gestão de ativos, assim pode-se concluir que, quando adotado e realizado conforme estabelecido, a recuperação dos rolos é viável.

\section{REFERÊNCIAS}

BAPTISTA, André Luís de Brito. Aspectos metalúrgicos na avaliação da usinabilidade de aços. Rem: Revista Escola de Minas, v. 55, n. 2, p. 103-109, 2002.

BLAU, Peter J. Elevated-temperature tribology of metallic materials. Tribology

International, v. 43, n. 7, p. 1203-1208, 2010.

BRESCIANI FILHO, Ettore et al. Conformação plástica dos metais. 1. ed. São Paulo: EPUSP, 2011.

COELHO, Gilberto Carvalho. Lingotamento Contínuo. Lorena: Universidade de São Paulo, 2013.

DIFERRO. Construção mecânica: catálogo aços baixa liga. DIFERRO, 2018. Disponível em:

<https://www.diferro.com.br/igc/uploadAr/FileProcessingScripts/PHP/UploadedFiles/catalog oconstrucao-mecanica-diferro-21552670907-305427.pdf>. Acesso em: 25 out. 2019.

FOSTER, J. Materials for Wear-Resistant Surfaces. Nuclear Engineering and Design, v. 17, n. 2, p. 205-246, 1971.

GENTIL, Vicente. Corrosão. 5. ed. São Paulo: LTC, 2007. 
NELSON, Tracy. W.; LIPPOLD, J. C.; MILLS, M. J. Nature and Evolution of the Fusion Boundary in Ferritic-Austenitic Dissimilar Metal Welds - Part 2 : On-Cooling Transformations. Welding Journal, p. 267s-277s, out. 2000.

PHILLIPS, David H. Welding Engineering: An Introduction. Nova Jersey: Wiley, 2015. RODRIGUES, Enilson dos Anjos. Recuperação de rolos da laminação. In: 54 Seminário de Laminação e Conformação. São Paulo: ABM, vol.54, n.54, 2017. P. 108-113.

ROY, Manish. Surface engineering for enhanced performance against wear. Nova Iorque: Springer, 2013.

ULUTAN, Mustafa et al. Microstructure and Wear Behavior of TIG Surface-Alloyed AISI 4140 Steel. Tribology Transactions, v. 54, n. 1, p. 67-79, 2011. 